\title{
Apotopes and the Biliary Specificity of Primary Biliary Cirrhosis
}

\author{
Ana Lleo, ${ }^{1,2}$ Carlo Selmi, ${ }^{1,2}$ Pietro Invernizzi, ${ }^{1,3}$ Mauro Podda, ${ }^{2}$ Ross L. Coppel, ${ }^{4}$ Ian R. Mackay, ${ }^{5}$ Gregory J. Gores, ${ }^{6}$ \\ Aftab A. Ansari, ${ }^{7}$ Judy Van de Water, ${ }^{1}$ and M. Eric Gershwin ${ }^{1}$
}

Primary biliary cirrhosis (PBC) is characterized by antimitochondrial antibodies (AMAs), directed to the 2 component of the pyruvate dehydrogenase complex (PDC-E2). Notwithstanding the presence of mitochondria in virtually all nucleated cells, the destruction in PBC is limited to small intrahepatic bile ducts. The reasons for this tissue specificity remain unknown, although biliary epithelial cells (BECs) uniquely preserve the PDC-E2 epitope following apoptosis. Notably, PBC recurs in an allogeneic transplanted liver, suggesting generic rather than host PBCspecific susceptibility of BEC. We used cultured human intrahepatic BECs (HIBECs) and other well-characterized cell lines, including, $\mathrm{HeLa}, \mathrm{CaCo}-2$ cells, and nontransformed human keratinocytes and bronchial epithelial cells, to determine the integrity and specific localization of PDC-E2 during induced apoptosis. All cell lines, both before and after apoptosis, were tested with sera from patients with $\mathrm{PBC}(\mathrm{n}=30)$, other autoimmune liver and rheumatic diseases $(\mathrm{n}=$ 20), and healthy individuals $(n=20)$ as well as with a mouse monoclonal antibody against PDC-E2 and AMA with an immunoglobulin A isotype. PDC-E2 was found to localize unmodified within apoptotic blebs of HIBECs, but not within blebs of various other cell lineages studied. The fact that AMA-containing sera reacted with PDC-E2 on apoptotic BECs without a requirement for permeabilization suggests that the autoantigen is accessible to the immune system during apoptosis. Conclusion: Our data indicate that the tissue (cholangiocyte) specificity of the autoimmune injury in $\mathrm{PBC}$ is a consequence of the unique characteristics of HIBECs during apoptosis and can be explained by exposure to the immune system of intact immunoreactive PDC-E2 within apoptotic blebs. (HEPATOLOGY 2009;49:871-879.)

\footnotetext{
Abbreviations: $A B$, apoptotic body; AIH, autoimmune hepatitis; $A M A$, antimitochondrial antibody; $B E C$, biliary epithelial cell; $B r E p C$, bronchial epithelial cells; CHC, chronic hepatitis C; DAPI, 4', 6-diamidino-2-phenylindole; FBS, fetal bovine serum; GCDC, sodium glycochenodeoxycholate; HIBEC, human intrahepatic biliary epithelial cell; $M$, mitochondria; $m A b$, monoclonal antibody; $P B C$, primary biliary cirrhosis; PBS, phosphate-buffered saline; PBS-T, PBS with 0.5\% Tween 20; PDC-E2, E2 component of the pyruvate dehydrogenase complex; PSC, primary sclerosing cholangitis; SLE, systemic lupus erythematosus; UVB, ultraviolet B light.

From the ${ }^{1}$ Division of Rheumatology, Allergy, and Clinical Immunology, University of California at Davis, Davis, CA, ${ }^{2}$ Division of Internal Medicine, IRCCSIstituto Clinico Humanitas, University of Milan, Rozzano, Milan, Italy; ${ }^{3}$ Division of Internal Medicine, Hepatobiliary Immunopathology Unit, IRCCS-Istituto Clinico Humanitas, Rozzano, Milan, Italy; ${ }^{4}$ Department of Medical Microbiology and ${ }^{5}$ Department of Biochemistry and Molecular Biology, Monash University, Melbourne, Australia; ${ }^{6}$ Division of Gastroenterology and Hepatology, Mayo Clinic College of Medicine, Rochester, MN; and ${ }^{7}$ Department of Pathology, Emory University School of Medicine, Atlanta, GA.

Received September 30, 2008; accepted October 31, 2008.

Financial support provided by National Institutes of Health grants DK70004 and DK39588.

Address reprint requests to: M. Eric Gershwin, M.D., Division of Rheumatology, Allergy and Clinical Immunology, University of California at Davis School of Medicine, Genome and Biomedical Sciences Facility, 451 Health Sciences Drive, Suite 6510, Davis, CA 95616. E-mail: megershwin@ucdavis.edu; fax: 530-752-4669. Copyright (C) 2009 by the American Association for the Study of Liver Diseases. Published online in Wiley InterScience (www.interscience.wiley.com). DOI 10.1002/hep.22736

Potential conflict of interest: Nothing to report.
}

poptotic cells are normally efficiently cleared after A engulfment by "professional" phagocytes followed by an anti-inflammatory response. ${ }^{1,2}$ When such uptake is impaired, cell lysis can release intracellular components that are a potential source of autoantigenic stimulation ${ }^{3-6}$ and autoimmunity onset. ${ }^{7-9}$ The presence of intact autoantigens within apoptotic blebs, ${ }^{10}$ their participation in the processes involved in autoantigen presentation, ${ }^{11}$ and the activation of innate immunity through macrophage cytokine secretion in concert ${ }^{12}$ are likely links between apoptosis and autoimmunity. Of relevance to the autoimmune liver disease primary biliary cirrhosis (PBC), Odin and colleagues demonstrated that, following apoptosis of biliary epithelial cells (BECs), the autoantigenic E2 subunit of the pyruvate dehydrogenase complex (PDC-E2) remains immunologically intact and still recognizable as such by antimitochondrial autoantibodies (AMAs). ${ }^{13}$ It is reasoned that absence of glutathiolation ${ }^{13}$ may contribute to this unique feature of the BEC.

We reasoned that immune-mediated $\mathrm{BEC}$ destruction would be accentuated if PDC-E2 were preserved in blebs during apoptosis. Indeed, this could lead to impaired clearance of such apoptotic cells, thus provoking an in- 
nate immune response and even the autoimmune destruction of bile ducts. This scenario would help explain the recurrence of $\mathrm{PBC}$ following orthotopic liver transplantation, ${ }^{14}$ as well as the therapeutic failure of immunosuppressive agents. ${ }^{15}$ We report here the cellular topology of PDC-E2 during apoptosis of cultured human intrahepatic BECs (HIBECs) and other non-BEC cells. Our findings demonstrate that PDC-E2 is localized intact within blebs of apoptotic HIBECs and is thereby accessible to the immune system. We hypothesize that the unique HIBEC apoptotic features allow the exposure of a potent intracellular autoantigen to the $\mathrm{PBC}$-associated multilineage autoimmune response that leads to the tissue-specific autoimmune injury.

\section{Patients and Methods}

Human Sera and Antibodies. After informed consent was given, serum samples were obtained from patients diagnosed with $\mathrm{PBC}(n=30)$, systemic lupus erythematosus (SLE; $n=5$ ), autoimmune hepatitis (AIH, $n=5$ ), primary sclerosing cholangitis (PSC, $n=$ 5), chronic hepatitis $\mathrm{C}(\mathrm{CHC}, n=5)$, and healthy individuals $(n=10)$. PBC sera included 20 randomly chosen AMA-positive cases and 10 well-defined patients who were AMA-negative; thus, the proportion of AMA-negative sera utilized in this study is significantly higher than the normally expected frequency because these were specifically sought for this study. The diagnosis of all cases was based on established criteria for PBC, ${ }^{16}$ SLE, ${ }^{17}$ $\mathrm{AIH},{ }^{18} \mathrm{PSC},{ }^{19}$ and by detection of serum hepatitis $\mathrm{C}$ virus (HCV) RNA for $\mathrm{CHC}$ by polymerase chain reaction. As expected, $90 \%$ (27 of 30 ) of $\mathrm{PBC}$ cases were women and $70 \%$ were taking ursodeoxycholic acid as the sole treatment at the time of enrollment. The mean age was $63 \pm$ 10 years, and 17 of 30 patients had advanced PBC (histological stages III-IV). These clinical features did not differ between patients with AMA-positive or AMA-negative PBC (data not shown).

Antibody Reagents. Serum anti-PDC-E2 antibodies were tested using our well-defined assays with recombinant antigens, as explained below. ${ }^{20-22}$ We also utilized a previously described mouse monoclonal antibody (mAb) against PDC-E2, clone $2 \mathrm{H}-4 \mathrm{C} 8 .{ }^{23}$ Secondary antibodies Cy3-labeled anti-human-immunoglobulin $\mathrm{G}$ ( $\mathrm{IgG})$, anti-human-IgA, and anti-mouse-IgG were purchased from Jackson ImmunoResearch (West Grove, PA). Normal mouse IgG was obtained from Invitrogen (Carlsbad, CA) and fluorescein isothiocyanate (FITC)-labeled annexin-V was obtained from BD Pharmingen (San Jose, CA). Monoclonal anti-human caspase-3 antibody was purchased from R\&D Systems (Minneapolis, MN). Neg- ative controls were used throughout and included sera from healthy individuals. Additionally, we purified IgAAMA from a patient diagnosed with $\mathrm{PBC}$ and a monoclonal gammopathy with high levels of IgA-AMA using Jacalin-agarose beads (Pierce, Rockford, IL) following the manufacturer's instructions. Serum IgA from a healthy subject was used as a control.

Detection of $A M A$. An established optimal amount $(16 \mu \mathrm{g})$ of purified recombinant PDC-E2 was loaded onto a $10 \%$ mini protein gel (Bio-Rad Laboratories, Hercules, CA), fractionated at $170 \mathrm{~V}$ for 1 hour, and transferred overnight onto nitrocellulose membranes that were then cut into strips. AMA detection was performed as described. ${ }^{24}$ The samples to be analyzed included sera from patients with $\mathrm{PBC}$ at an optimal dilution of 1:2000, monoclonal AMA ( $10^{-4}$ dilution), pooled AMA of $\operatorname{IgA}$ isotype (dilution 1:2000), and control IgA (1:2000). Blots were exposed on photographic membranes and images were digitized with a FluorTech 8900 gel doc system (Alpha Innotech, San Leandro, CA) equipped with a chemiluminescent filter. The absence of AMA was further confirmed in the sera of the patients who were AMAnegative, using our standardized enzyme-linked immunosorbent assay (ELISA) and pMIT-3 antigens. ${ }^{25}$

Cell Lines and Culture Conditions. The cells studied were cultured HIBECs, two human epithelial nontransformed primary cell cultures (human keratinocytes and bronchial epithelial cells [BrEpCs]) purchased from ScienCell (San Diego, CA) and two human tumor-derived laboratory cell lines, HeLa cells and $\mathrm{CaCo}-2$ cells purchased from American Type Culture Collection (Manassas, VA). HIBECs were cultured in sterile medium supplemented with $2 \%$ fetal bovine serum (FBS), epithelial cell growth supplement (ScienCell, San Diego, CA), and $1 \%$ penicillin in cell culture flasks coated with polyL-lysine (Sigma-Aldrich, St Louis, MO). The other two epithelial cells were cultured under the same conditions in absence of FBS, as recommended by the manufacturer. HeLa and CaCo-2 cells were cultured using low glucose Dulbecco's modified Eagle medium, supplemented with $10 \%$ FBS for HeLa cells and $20 \%$ for $\mathrm{CaCo}-2$ cells, gentamicin $(6 \mu \mathrm{g} / \mathrm{mL})$, sodium pyruvate $(110 \mathrm{mg} / \mathrm{L})$, and L-glutamine $(2 \mathrm{mM})$. Cells were cultured at $37^{\circ} \mathrm{C}$ in a humidified $5 \% \mathrm{CO}_{2}$ incubator.

HIBECs were isolated from human liver tissue by the supplier and cryopreserved immediately after purification. This primary cell culture was characterized by an immunofluorescence method with antibodies to cytokeratin 18 , cytokeratin 19 , and vimentin which stained more than $90 \%$ of the cells. All experiments on HIBECs were performed between cell passage 2 and 5 .

Induction of Apoptosis. We used biliary salts (BS) to 
induce apoptosis. ${ }^{26}$ To establish optimal conditions for the induction of apoptosis, we incubated all the cells types at $37^{\circ} \mathrm{C}$ for $1,2,3$, and 4 hours using different concentrations (100 $\mu \mathrm{M}, 500 \mu \mathrm{M}, 1 \mathrm{mM}$, and $2 \mathrm{mM}$ ) of sodium glycochenodeoxycholate (GCDC; Sigma-Aldrich) added to normal culture medium, and in absence of serum and growth factors. ${ }^{26} \mathrm{BS}$ failed to induce any apoptotic effect in HeLa and Caco- 2 cells so, in these transformed cell lines, apoptosis induction was performed by ultraviolet $\mathrm{B}$ light (UVB) irradiation, at $1650 \mathrm{~J} / \mathrm{m}^{2}$ for HeLa cells and $2200 \mathrm{~J} / \mathrm{m}^{2}$ for CaCo-2 cells, followed by incubation in fresh media for 8 (HeLa) or $16(\mathrm{CaCo}-2)$ hours. ${ }^{13}$ Apoptosis was also induced in HIBECs by UVB irradiation $\left(1650 \mathrm{~J} / \mathrm{m}^{2}\right)$ followed by incubation in fresh medium for 6 hours.

Quantification of Apoptosis by Flow Cytometry. The cells to be analyzed for apoptosis were suspended in $200 \mu \mathrm{L}$ of buffer containing $10 \mathrm{mM}$ Hepes/ $\mathrm{NaOH}$ (pH 7.4), $140 \mathrm{mM} \mathrm{NaCl}$, and $2.5 \mathrm{mM} \mathrm{CaCl}_{2}$. A total of $1 \times$ $10^{6}$ cells were stained for 15 minutes at room temperature in the dark with FITC-labeled annexin-V and with propidium iodide (BD Pharmingen, San Jose, CA) to discriminate apoptotic from necrotic cells. The samples were immediately analyzed by flow cytometry, and at least 10,000 events were counted. Stained cells were assessed on a fluorescence-activated cell sorting (FACS) FACScan flow cytometer (BD Immunocytometry Systems, San Jose, CA) upgraded by Cytec Development (Fremont, CA). Acquired data were analyzed with CellQuest Pro (BD Immunocytometry Systems) and FlowJo (Tree Star Inc., Ashland, OR) software packages.

Immunostaining and Confocal Microscopy. Cells were washed twice with phosphate-buffered saline (PBS) and incubated with FITC-labeled annexin-V at 1:10 dilution for 15 minutes at room temperature (RT) in the dark. The samples were then fixed in 3.7\% formaldehyde ( 5 minutes at RT), permeabilized with $0.2 \%$ Triton $\mathrm{X}-100$ (5 minutes at RT) and blocked for 30 minutes at RT with $1 \times$ Universal blocking solution (Bio-Genex). Immunofluorecence staining was performed with human sera diluted 1:40 or monoclonal antibody diluted 1:80 (overnight, $4^{\circ} \mathrm{C}$ ), followed by Cy3-labeled secondary antibody diluted 1:500 for 1 hour at RT. The cells were costained with 4',6-diamidino-2-phenylindole (DAPI; Invitrogen, Carlsbad, CA) to visualize nuclear degeneration. All samples were stained when at $80 \%$ confluence; samples with less than 100 cells were excluded. Identical settings were used for all samples. Controls consisting of incubation of cells with developing secondary antibody alone did not demonstrate any detectable staining under the same conditions.
Staining of nonapoptotic and apoptotic HIBECs was also performed in the absence of membrane-perforating agent. The same protocol previously described was followed but Triton X-100 was omitted. Immunofluorescence-labeled samples were examined using a Pascal Zeiss confocal laser scanning microscope with a $100 \times$ oil-immersion objective.

Isolation and Immunoblot Analysis of Apoptotic Bodies. After induction of apoptosis, subcellular fragments were isolated by filtration and ultracentrifugation as described elsewhere. ${ }^{10}$ Briefly, the cell culture supernatant fluid was collected after apoptosis induction. Two additional centrifugation steps ( $500 \mathrm{~g}$ for 5 minutes) were performed in order to remove the remaining cells. The supernatant fluid was then passed through a $1.2 \mu \mathrm{m}$ nonpyrogenic, hydrophilic syringe filter. After centrifugation at $100,000 \mathrm{~g}$ for 30 minutes, the pellet containing apoptotic bodies $(\mathrm{AB})$ was resuspended in lysis buffer containing a protease inhibitor cocktail (Roche Diagnostics, Indianapolis, IN). Lysis was performed for 30 minutes on ice.

Protein content of the samples was determined by the BCA (bicinconic acid) assay using a Nanodrop ND-1000 ultraviolet-visible Spectrophotometer (NanoDrop Technologies, Wilmington, DE). Each sample $(20 \mu \mathrm{g})$ was diluted in loading buffer and subjected to standard sodium dodecyl sulfate polyacrylamide gel electrophoresis. After transfer to polyvinylidene fluoride membranes, PDC-E2 was detected using the monoclonal antibody previously described (clone $2 \mathrm{H}-4 \mathrm{C} 8$ ) ${ }^{23}$ and AMA-positive sera with two different AMA isotypes.

\section{Results}

Apoptosis in HIBECs. Apoptosis rates were evaluated in all cell lines by FACS (annexin $\mathrm{V}$ and propidium iodide double staining) and immunofluorescence. Apoptotic cells were identified with confocal microscopy by morphological criteria: high nuclear density, chromatin condensation, and nuclear fragmentation revealed with DAPI, and characteristic blebbing of the cell membrane revealed with annexin- $\mathrm{V}$; on the basis of these characteristics, an apoptotic index was established as: (DAPI-apoptotic nuclei/total nuclei) $\times 100$.

Bile salts (BS) accumulating in the human liver in the course of cholestatic conditions trigger liver injury and subsequent fibrosis, and it has been demonstrated that a constituent of the hydrophobic BS, glycochenodeoxycholate (GCDC), induces apoptosis of hepatocytes starting at a concentration of $50 \mu \mathrm{M} .{ }^{27}$ GCDC has also an apoptotic effect in cholangiocytes. ${ }^{26}$ The use of $1 \mathrm{mM}$ GCDC in the absence of serum, or growth factors, induced apoptosis in 39\% of HIBECs, whereas UVB irra- 

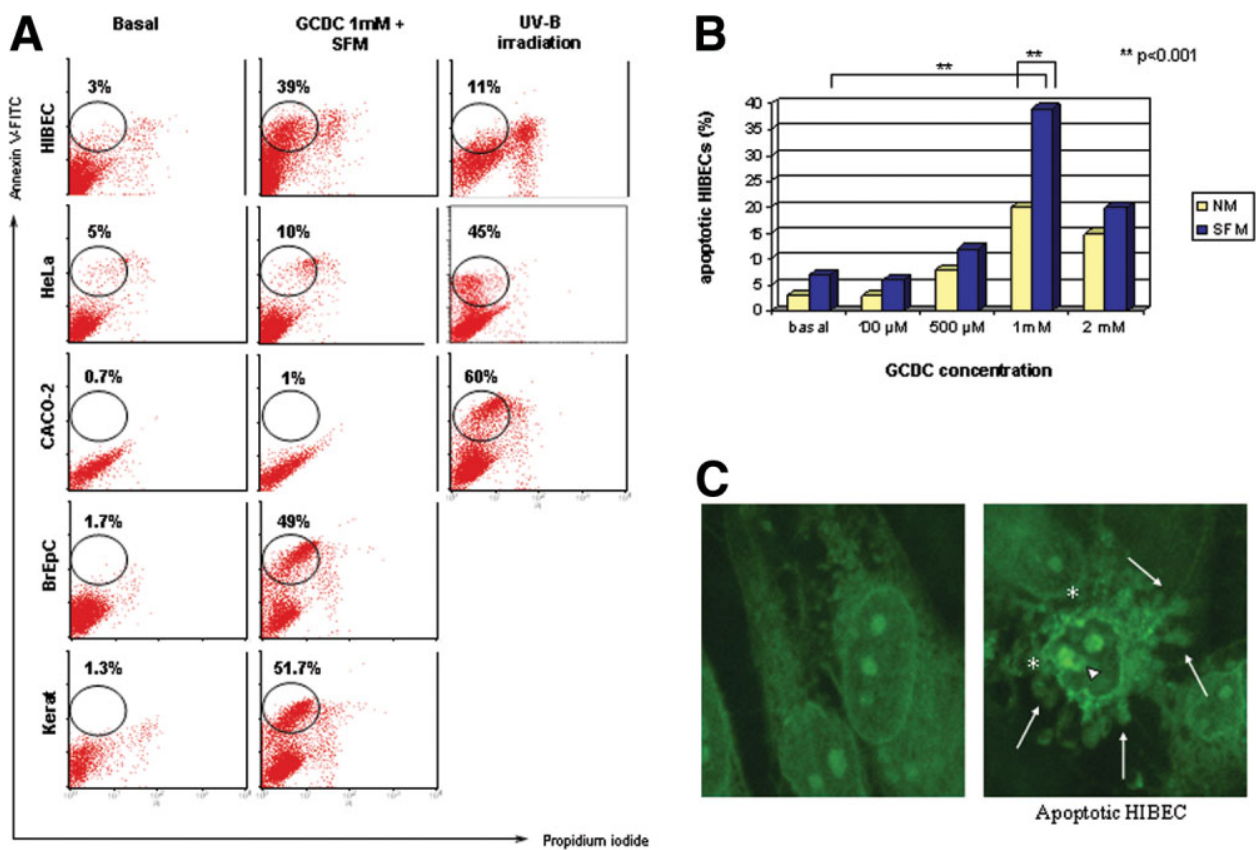

Fig. 1. Human intrahepatic biliary epithelial cells (HIBECs) and four other cell types were cultured in normal media (NM) or serum-free media (SFM) under optimal conditions to induce apoptosis, either by exposure to bile salts (GCDC) or ultraviolet B (UVB) irradiation (see Patients and Methods). (A) Induction of apoptosis was investigated by flow cytometry after double staining with FITC-labeled annexin $\mathrm{V}$ and propidium iodide. The use of 1 mM GCDC in the absence of serum, or growth factors, induced apoptosis in 39\% of HIBECs, $49 \%$ of BrEpCs, and $51.7 \%$ of keratinocytes, whereas no significant apoptotic response was observed in transformed cell lines. UVB irradiation induced apoptosis in just $11 \%$ of HIBECs and a higher level of double positive propidium iodide/annexinV cells, most probably referable to necrotic cells. (B) Different concentrations of GCDC in NM or SFM were tested to establish proapoptotic concentrations for HIBECs, with $1 \mathrm{mM}$ proving optimal. (C) HIBECs after exposure to GCDC 1 mM in SFM were assessed by confocal microscopy, revealing typical apoptotic morphology with blebbing of the membrane $\left(^{*}\right)$, nucleolar degeneration (short arrow), and apoptotic fragments (long arrow). A $100 \times$ oil-immersion objective was used.

diation $\left(1650 \mathrm{~J} / \mathrm{m}^{2}\right.$ followed by incubation in fresh medium at $37^{\circ} \mathrm{C}$ for 6 hours) induced apoptosis in just $11 \%$ of HIBECs; moreover, in our experience, a higher level of double-positive propidium iodide/annexinV cells, most probably referable to necrotic cells, was generated following UVB irradiation compared to BS in HIBECs (Fig. 1A). Under both sets of conditions, membrane blebbing and apoptotic fragments were observed in HIBECs using confocal microscopy (Fig. 1C). The levels of apoptosis in HeLa and CaCo-2 cells after UVB irradiation were similar to those reported in the literature, i.e., $45 \%$, and 60\%, respectively. ${ }^{28}$ GCDC induced apoptosis in $49 \%$ of BrEpCs and $52 \%$ of keratinocytes. On the other hand, no substantial level of apoptosis was observed in HeLa and $\mathrm{CaCo}-2$ cells after incubation with BS.

In conclusion, GCDC at $1 \mathrm{mM}$ in serum-free medium was chosen to induce apoptosis in HIBECs, keratinocytes, and BrEpCs, whereas apoptotic HeLa and $\mathrm{CaCo}-2$ cells were generated by UVB irradiation. To exclude that a different method of apoptosis was the reason for different expression of PDC-E2, staining with $\mathrm{mAb}$ against PDC-E2 using UVB-irradiated HIBECs was performed and the same results were observed.
PDC-E2 Is Not Altered in Apoptotic HIBECs and Localizes Within Blebs. The localization of PDC-E2 was studied in apoptotic HIBECs by indirect immunofluorescence and compared with other human cell lines. Apoptotic cells were identified by morphological criteria; DAPI staining was preferred over the use of terminal deoxynucleotidyl transferase-mediated dUTP nick-end labeling (TUNEL) to detect apoptotic cells because of its greater specificity, since TUNEL identifies fragmented DNA in both apoptotic and necrotic cells and hence may overestimate the number of apoptotic cells. First, HIBECs were stained with sera from patients with PBC $(n=$ 20) before and after induction of apoptosis, using both IgG and IgA AMA isotypes. As expected, nonapoptotic cells presented the typical punctuate cytoplasmic mitochondrial immunofluorescence pattern (Fig. 2A), negative staining for annexin- $\mathrm{V}$, and normal nuclear morphology. After staining was performed under the same conditions following induction of apoptosis with 1 $\mathrm{mM} \mathrm{GCDC}$ in the absence of serum and growth factors, apoptotic HIBECs expressed positive PDC-E2 staining that could be localized with annexin $\mathrm{V}$ within apoptotic blebs and fragments (Fig. 2B). No detectable staining was 

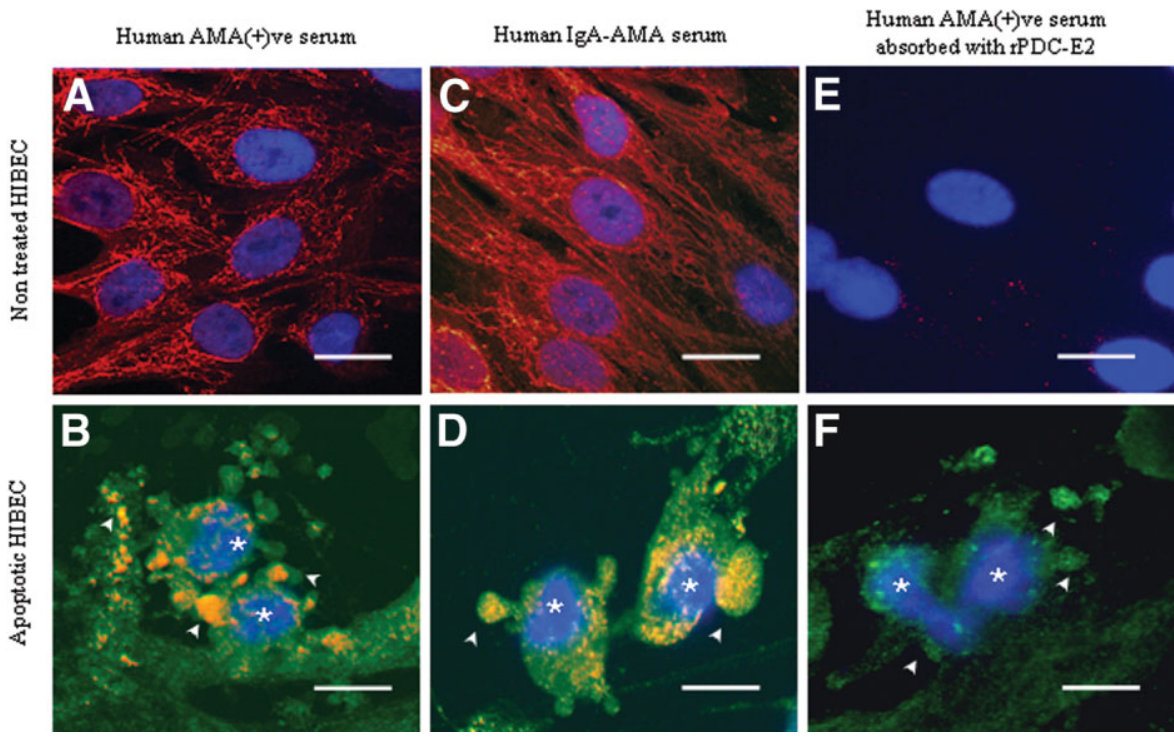

Fig. 2. Staining of nonapoptotic or apoptotic HIBECs using an AMA-positive PBC serum $(A, B)$, serum from a patient with PBC with monoclonal production of IgA-AMA (C,D), and using the same AMA-positive serum after absorbtion with recombinant PDC-E2 (E,F). The immunofluorescence staining was performed with three fluorochromes: Cy3-conjugated secondary antibody (red, yellow-orange when costained with green), FITC-labeled annexin-V (green), and DAPI (blue) for apoptosis detection. Apoptotic cells $\left({ }^{*}\right)$ were identified by morphological criteria: high nuclear density, chromatin condensation and nuclear fragmentation revealed with DAPI (blue), and characteristic blebbing of the cell membrane revealed with annexin-V (green). Positive staining of blebs and apoptotic fragments (arrows) was observed using unabsorbed PBC sera and was virtually absent after absorption. Apoptosis was confirmed in all experiments $\left({ }^{*}\right)$. Scale bar represents $20 \mu \mathrm{m}$.

noted on cells treated with either the secondary antibody alone or with normal mouse IgG instead of the $\mathrm{mAb}$ (data not shown). These findings were also reproduced in HIBECs following UVB irradition and incubated in fresh media at $37^{\circ} \mathrm{C}$ for 6 hours (data not shown).

Immunofluorescence with murine mAb confirmed the results obtained with the human sera, and apoptotic HIBECs retained the PDC-E2-specific staining within the apoptotic blebs. There were no differences in staining using each of the AMA-positive sera from the patients with $\mathrm{PBC}$ according to age, disease stage, or therapy with ursodeoxycholic acid, and the staining patterns were similar to those obtained with the AMA-IgA (Fig. 2C,D). Preincubation overnight with human recombinant PDC-E2 completely removed the capacity of the sera to stain normal and apoptotic cells (Fig. 2). Serum samples from patients with AMA-negative PBC $(n=10)$, AIH $(n=5)$, SLE $(n=5)$, PSC $(n=5), \operatorname{CHC}(n=5)$, and healthy controls $(n=10)$ failed to produce any staining of HIBECs (Table 1).

Localization of PDC-E2 Within Apoptotic Blebs Is Specific for HIBECs. PDC-E2 localization was investigated using the clone $2 \mathrm{H}-4 \mathrm{C} 8 \mathrm{mAb}$ and sera from patients with $\mathrm{PBC}$ and controls using a variety of different human cell lines (Table 1, Fig. 3). All experiments were performed before and after induction of apoptosis under the same conditions as specified above for HIBECs. Before apoptosis induction, each of the cell lines manifested the typical cytoplasmic staining of mitochondria when the clone $2 \mathrm{H}-4 \mathrm{C} 8 \mathrm{mAb}$ was used (Fig. 3, upper row). Following apoptosis induction, none of the control cell lines had PDC-E2 staining (Fig. 3, lower row). None of the cell lines used demonstrated detectable cytoplasmic staining when sera from patients with AMA-negative PBC, AIH, SLE, PSC, CHC, or healthy controls were used (data not shown).

These morphological observations were corroborated by western blot analysis wherein PDC-E2 was readily de-

Table 1. Prevalence of staining for PDC-E2 in blebs of various cell types undergoing apoptosis using $\mathrm{PBC}$ and control sera. of note, specific bleb staining was observed in virtually all HIBEC when AMA-positive PBC sera were used.

This staining was not observed in non-apoptotic cells.

Fisher's Exact Test was used to calculate statistical significance between HIBEC and the other cell types.

\begin{tabular}{lrc}
\hline & HIBEC & Control cells* \\
\hline PBC AMA +ve & $20 / 20$ & $0 / 40^{* *}$ \\
PBC AMA -ve & $0 / 10$ & $0 / 20$ \\
Control sera*** & $0 / 30$ & $0 / 60$ \\
\hline
\end{tabular}

* Control cells include in equal distribution, transformed cells (HeLa and CaCo-2 cells) and non-transformed human epithelial cells (keratinocytes and bronchial epithelial cells).

** $p$ value $<0.0001$ compared to HIBEC

*** One third of the control sera were from healthy subjects, and two thirds were from patients with systemic lupus erythematosus, autoimmune hepatitis, primary sclerosing cholangitis or chronic hepatitis $\mathrm{C}$. 
Table 2. Number of apoptotic cells in which blebs contain PDC-E2. The apoptotic cells were stained as described with sera from PBC AMA positive patients $(n=20)$. Values are expressed as mean \pm SD. Apoptotic index was derived from DAPI-apoptotic nuclei/total nuclei x 100. An individual apoptotic cell was considered positive when PDC-E2 staining was observed in at least one of its blebs. Student's t-test was used to calculate $p$ values.

\begin{tabular}{lcc}
\hline \multicolumn{1}{c}{ Cell type } & $\begin{array}{c}\text { Apoptotic } \\
\text { index }\end{array}$ & $\begin{array}{c}\text { Cells with positive staining } \\
\text { for PDC-E2 within blebs }\end{array}$ \\
\hline HIBEC & $38 \pm 2.2$ & $88 \pm 0.7$ \\
Keratinocytes & $51 \pm 0.7$ & $0 \pm 1.3^{*}$ \\
BrEpC & $48 \pm 1.7$ & $0 \pm 0.4^{*}$ \\
HeLa & $42 \pm 1.2$ & $0 \pm 0.7^{*}$ \\
CaCO-2 & $61 \pm 3.5$ & $0 \pm 0.3^{*}$ \\
\hline
\end{tabular}

$* p$ value $<0.0001$ compared to HIBEC

tected in lysates of isolated apoptotic bodies obtained from HIBECs, whereas no such reactivity was observed in lysates from HeLa cells and BrEpCs (Fig. 4).

PDC-E2 in Apoptotic Blebs Is Accessible to Antibody Recognition. AMA staining in normal cells requires the use of a perforating agent due to the conservation of membrane integrity, but we hypothesize that during apoptosis the mitochondrial antigen became accessible to the immune system. To determine whether the permeabilization agents were responsible for the access of autoantibodies to PDC-E2 within blebs, we stained HIBECs with the clone $2 \mathrm{H}-4 \mathrm{C} 8 \mathrm{mAb}$ in the absence of Triton X-100. Results obtained showed that while the absence of Triton X-100 did not modify the positive staining of blebs in apoptotic HIBECs (Fig. 5), no differences were observed in the other cell lines because all of them lose AMA staining during apoptosis. These results were obtained with 12 of 20 AMA-positive PBC samples whereas sera from patients with AMA-negative PBC $(n=5), \operatorname{AIH}(n=5), \operatorname{SLE}(n=5), \operatorname{PSC}(n=5)$, $\mathrm{CHC}(n=5)$, or healthy controls $(n=5)$, or the use of secondary antibody alone failed to demonstrate any staining (Table 3).

\section{Discussion}

We demonstrate in this report that PDC-E2, the major AMA autoantigen, is detectable in its antigenically reactive form within apoptotic blebs, specifically in cultured human BECs and not in other cell types, thus providing one explanation for the organ-specific pathology noted in human PBC. We thus suggest that the unique characteristics of BECs during apoptosis might constitute the pathogenic link between the ubiquitous distribution and high degree of conservation across species of the AMA autoantigen and the organ specificity of $\mathrm{PBC}$ pathology.

It has been previously reported that PDC-E2 remains intact and retains its immunogenicity during BEC apoptosis due to a cell lineage-specific lack of glutathiolation. ${ }^{13,29}$ This "apoptotic exposure" of PDC-E2 appears to be limited to BECs, and it may ultimately have a critical pathogenic relevance to both inductive and effector stages of PBC. The formation of apoptotic bodies and fragments is essential during apoptosis to limit the escape of intracellular content and preclude any ensuing immunological responses against intracellular autoantigens with inflammatory reactions. ${ }^{30,31}$ Nevertheless, apoptotic blebs and
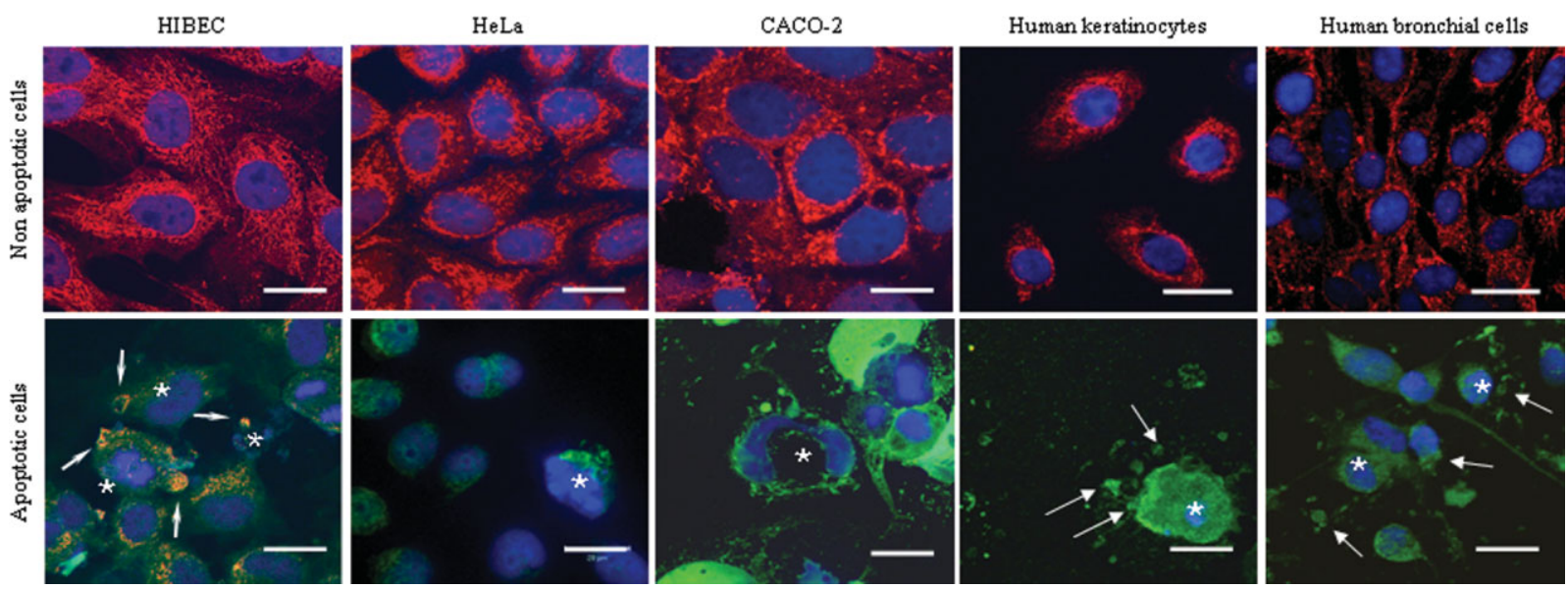

Fig. 3. Apoptosis-dependent anti-PDC-E2 staining in various human cell types, with nonapoptotic cells shown in the upper row and apoptotic cells in the lower row. Immunofluorescence staining was performed with three fluorochromes: mAb against PDC-E2 and Cy3-conjugated secondary antibody (red, yellow-orange when costained with green); FITC-labeled annexin-V (green); and DAPI (blue) for apoptosis detection. Apoptotic cells $(*)$ were identified as described in Fig. 2. Nonapoptotic cells (upper row) have a normal AMA pattern of immunofluorescence staining (red). Apoptotic cells (lower row) show differences between HIBECs that retained mitochondrial staining within blebs and fragments (arrow) after apoptosis, and other cell types (CACO-2 cells, HeLa cells, human keratinocytes, and human bronchial epithelial cells) that lost mitochondrial staining after apoptosis. A 100 $\times$ oil-immersion objective was used. Scale bar represents $20 \mu \mathrm{m}$. 


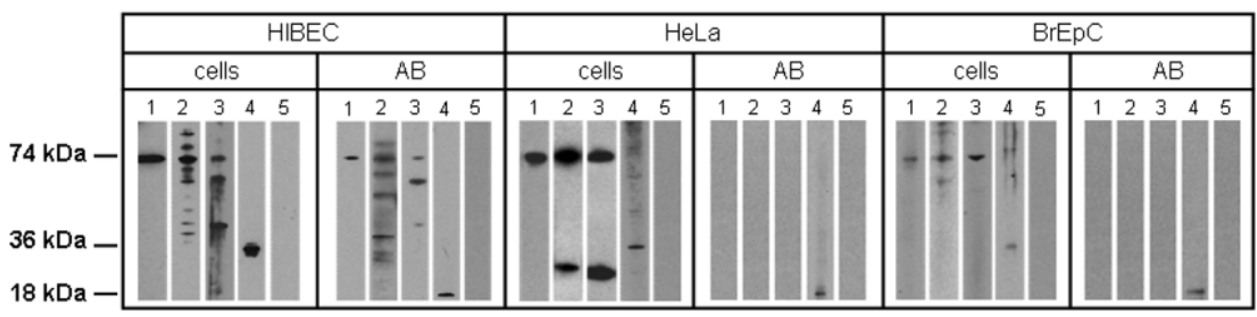

Fig. 4. Western blots show that PDC-E2 is localized unmodified within apoptotic bodies (AB) from HIBECs but not from other cell lineages. ABs were isolated by filtration and ultracentrifugation after induction of apoptosis (see Patients and Methods). PDC-E2 was detected by western blot in lysates obtained from nonapoptotic cells and ABs using (1) mAb against PDC-E2, (2) AMA-positive serum, (3) AMA-IgA isotype, (4) mAb against caspase-3, and (5) serum from a healthy control. PDC-E2 was detected in ABs from HIBECs when tested with mAb and with PBC sera of two different Ig isotypes. ABs from HeLa cells and BrEpCs did not show the presence of PDC-E2 whereas, as expected, lysates from nonapoptotic cells did so. The 18-kDa subunit of caspase-3 generated during apoptosis is localized within apoptotic blebs, and hence exposure to mAb to caspase-3 was used to validate formation of blebs.

fragments can under some circumstances constitute a major source of immunogens in autoimmune diseases that involve the targeting of ubiquitous autoantigens. ${ }^{32}$ Thus, dysregulation of apoptosis or the ineffective removal of apoptotic cells has been documented in patients with $\mathrm{SLE}^{4,7,33}$ and the development of antibody-mediated myocarditis of infants born to mothers with anti-SSA/RoSSB/La. ${ }^{7}$ Also, Kupffer cell engulfment of apoptotic bod-
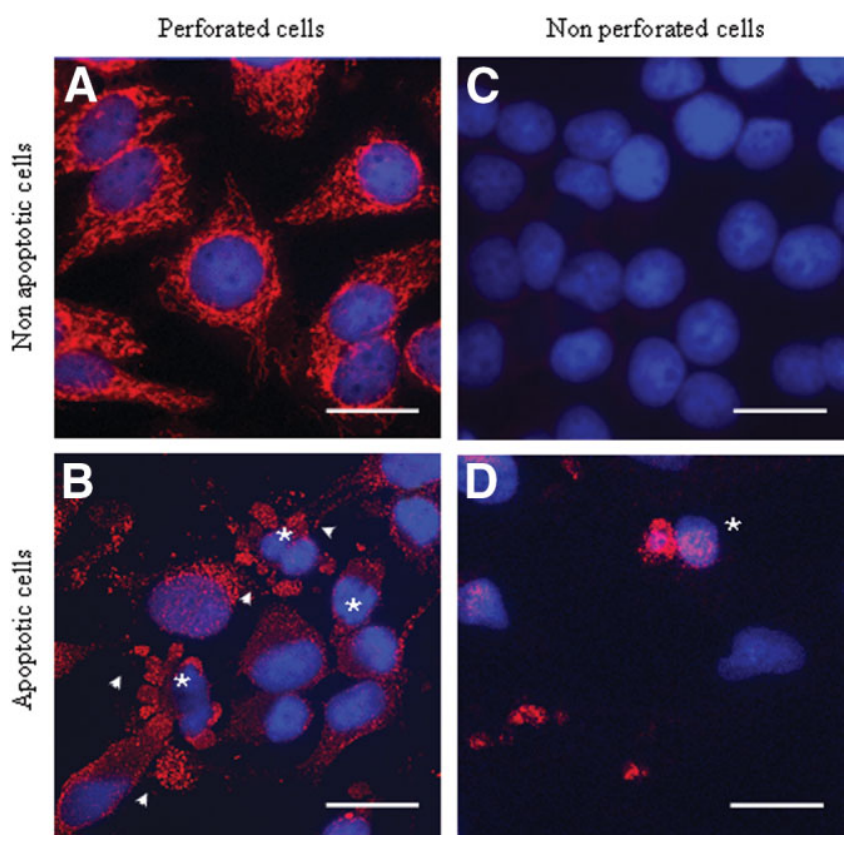

Fig. 5. Staining of nonapoptotic (upper row) and apoptotic (lower row) HIBECs in the absence or presence of a membrane-permeabilizing agent, Triton X-100. AMA staining in normal cells requires pemeabilization of the cell $(A)$; lacking this, no staining is observed due to retention of membrane integrity $(C)$; apoptotic HIBECs $\left({ }^{*}\right)$ stained with a mAb against PDC-E2, with positive staining demonstrable within the blebs (arrow) (B); apoptotic HIBECs retained the bleb staining even without permeabilization (D). No staining was observed with serum from patients with AMA-negative PBC, PSC, AlH, SLE, CHC, or healthy subjects (not shown). Scale bar represents $20 \mu \mathrm{m}$. ies from hepatocytes promotes inflammation and fibrogenesis. ${ }^{34,35}$

Our observations may help seal several remaining gaps in the understanding of induction and perpetuation of $\mathrm{PBC}$, albeit raising new questions. First, intact PDC-E2 in apoptotic fragments from BECs could be taken up by intrahepatic dendritic cells and transferred to regional lymph nodes for priming of cognate $T$ cells, thus initiating $\mathrm{PBC}$, but this attractive scenario still requires an explanation for the primum movens in the first place for apoptosis and this is likely not PBC-specific. Second, the accessibility of PDC-E2 within apoptotic blebs to autoantibodies appears to support the pathogenic role of AMA as well as T cells in the perpetuation of BEC injury, even though antibody titers do not correlate with the clinical features or stages of PBC, and AMA-negative patients are clinically indistinguishable from their AMA-positive counterparts. ${ }^{36}$ Nevertheless, the appearance of serum AMA does often herald disease onset sometimes by several years. ${ }^{16}$ Third, we can propose that PDC-E2 within apoptotic blebs will also be recognized by major histocompatibility complex class I-restricted CD8 $+\mathrm{T}$ cells; this point helps explain the BEC pathology in AMA-negative $\mathrm{PBC}$. Interestingly, our lab has recently demonstrated the presence of autoreactive T cells to PDC-E2 in patients with AMA-negative PBC. ${ }^{37}$ These data are also of particular relevance in view of the major pathogenic role of these cells in producing PBC-like liver lesions in animal models. ${ }^{38}$ Fourth, our findings are consistent with the likelihood that PBC cholangiocytes do not manifest any unique features that make them the target of autoimmunity ${ }^{37}$ noting the frequent recurrence of $\mathrm{PBC}$ following allogeneic liver transplantation. ${ }^{14}$ The latter two issues may ultimately be combined with the fact that the donor and recipient major histocompatibility complex class I alleles are major determinants of the allograft outcome. ${ }^{39}$ 
Table 3. Percentage of apoptotic HIBEC with positive staining for PDC-E2 in the presence or absence of a permeabilizating agent during the staining as described in the materials and methods. None of the control sera showed any positive staining. Values are expressed as mean \pm SD. Student's t-test was used to calculate $p$ values.

\begin{tabular}{lcccc}
\hline & $\begin{array}{c}\text { Proliferating } \\
\text { HIBEC }\end{array}$ & & \multicolumn{2}{c}{ Apoptotic HIBEC } \\
\cline { 2 - 2 } \cline { 5 - 5 } Sera (n) & Permeabilized & & permeabilized & Permeabilized \\
\hline mAb 2H-4C8 & $93 \pm 7$ & & $37 \pm 12$ & $91 \pm 5^{*}$ \\
PBC AMA + ve (20) & $88 \pm 6$ & & $33 \pm 7$ & $88 \pm 0.7^{*}$ \\
PBC AMA -ve (10) & 0 & & 0 & 0 \\
Control (30) & 0 & & 0 & 0 \\
\hline
\end{tabular}

$* \mathrm{P}$ value $<0.0001$ compared to non permeabilized apoptotic HIBEC

Fifth and ultimately, the ensuing $B$ and T cell autoreactive response may account for the perpetuation of the immune-mediated damage to BECs with a major role also played by elements of innate immunity which appears to be enhanced in PBC. 40,41

Our data imply that the postapoptotic release of intact mitochondrial autoepitopes in small bile ducts is one contributor to this specificity. Indeed, we should note that, as previously reported, the overexpression of $\mathrm{Bcl}-2$ (B cell lymphoma-2), specifically in apoptotic small BECs, inhibits PDC-E2 glutathiolation and prevents the loss of antigenicity. ${ }^{13,42}$ However, other factors have also been incriminated in playing a role in the selective destruction of small BECs. In particular, there are dramatic differences in expression of trefoils in small versus large bile ducts, suggesting not only an imbalance of homeostasis, but also a differential ability to repair or restitute cell damage. ${ }^{43}$

Our data also demonstrate that we are able to detect PDC-E2 without cell permeabilization. There are three explanations for this observation. First, PDC-E2 may leak out to the cell surface and is thus being detected on the cell membrane. Second, the cells undergoing apoptosis have holes in their cell membrane created by cellular proteases which allow passage into and localization of immunoglobulin in the bleb. Third, there may be a role for fragment crystallizable receptor-mediated uptake in the apoptotic cell. Future experiments will address these possibilities.

In conclusion, the evidence provided here leads to new scenarios in the pathogenesis of PBC and may constitute a credible link between the several convenient and inconvenient truths available thus far. ${ }^{37}$ However, it does not overcome all of the major challenges in PBC etiology, nor the need to ascertain the genetic basis of disease susceptibility and environmental triggers for cholangiocyte injury and apoptosis as an initial step in tolerance breakdown. Treatments that could modulate apoptosis ${ }^{44}$ should not be overlooked, and their assessment is warranted in recently established murine models for PBC. ${ }^{45-47}$

Acknowledgment: We thank Professor Terence M. Murphy, at the University of California Davis, for the use of the UVB irradiator and Thomas P. Kenny for his help and technical assistance.

\section{References}

1. Savill J, Dransfield I, Gregory C, Haslett C. A blast from the past: clearance of apoptotic cells regulates immune responses. Nat Rev Immunol 2002;2: 965-975.

2. Ravichandran KS, Lorenz U. Engulfment of apoptotic cells: signals for a good meal. Nat Rev Immunol 2007;7:964-974.

3. Torok NJ. Apoptotic cell death takes its toll. Hepatology 2007;46:13231325 .

4. Perniok A, Wedekind F, Herrmann M, Specker C, Schneider M. High levels of circulating early apoptic peripheral blood mononuclear cells in systemic lupus erythematosus. Lupus 1998;7:113-118.

5. Ruiz-Arguelles A, Brito GJ, Reyes-Izquierdo P, Perez-Romano B, SanchezSosa $S$. Apoptosis of melanocytes in vitiligo results from antibody penetration. J Autoimmun 2007:29:281-286.

6. Salunga TL, Cui ZG, Shimoda S, Zheng HC, Nomoto K, Kondo T, et al. Oxidative stress-induced apoptosis of bile duct cells in primary biliary cirrhosis. J Autoimmun 2007;29:78-86.

7. Clancy RM, Neufing PJ, Zheng P, O'Mahony M, Nimmerjahn F, Gordon TP, et al. Impaired clearance of apoptotic cardiocytes is linked to antiSSA/Ro and -SSB/La antibodies in the pathogenesis of congenital heart block. J Clin Invest 2006;116:2413-2422.

8. Allina J, Hu B, Sullivan DM, Fiel MI, Thung SN, Bronk SF, et al. T cell targeting and phagocytosis of apoptotic biliary epithelial cells in primary biliary cirrhosis. J Autoimmun 2006;27:232-241.

9. Lleo A, Invernizzi P, Selmi C, Coppel RL, Alpini G, Podda M, et al. Autophagy: highlighting a novel player in the autoimmunity scenario. J Autoimmun 2007;29:61-68.

10. Schiller M, Bekeredjian-Ding I, Heyder P, Blank N, Ho AD, Lorenz HM. Autoantigens are translocated into small apoptotic bodies during early stages of apoptosis. Cell Death Differ 2008;15:183-191.

11. Mandron M, Martin H, Bonjean B, Lule J, Tartour E, Davrinche C. Dendritic cell-induced apoptosis of human cytomegalovirus-infected fibroblasts promotes cross-presentation of pp65 to CD8 + T cells. J Gen Virol 2008;89:78-86.

12. Lucas M, Stuart LM, Savill J, Lacy-Hulbert A. Apoptotic cells and innate immune stimuli combine to regulate macrophage cytokine secretion. J Immunol 2003;171:2610-2615.

13. Odin JA, Huebert RC, Casciola-Rosen L, LaRusso NF, Rosen A. Bcl-2dependent oxidation of pyruvate dehydrogenase-E2, a primary biliary cirrhosis autoantigen, during apoptosis. J Clin Invest 2001;108:223-232.

14. Van de Water J, Gerson LB, Ferrell LD, Lake JR, Coppel RL, Batts KP, et al. Immunohistochemical evidence of disease recurrence after liver transplantation for primary biliary cirrhosis. HePATOLOGY 1996;24:10791084

15. Combes B, Emerson SS, Flye NL, Munoz SJ, Luketic VA, Mayo MJ, et al. Methotrexate (MTX) plus ursodeoxycholic acid (UDCA) in the treatment of primary biliary cirrhosis. HePATOLOGY 2005;42:1184-1193.

16. Kaplan MM, Gershwin ME. Primary biliary cirrhosis. N Engl J Med 2005;353:1261-1273.

17. Hochberg MC. Updating the American College of Rheumatology revised criteria for the classification of systemic lupus erythematosus. Arthritis Rheum 1997;40:1725.

18. Alvarez F, Berg PA, Bianchi FB, Bianchi L, Burroughs AK, Cancado EL, et al. International Autoimmune Hepatitis Group Report: review of criteria for diagnosis of autoimmune hepatitis. J Hepatol 1999;31:929-938. 
19. Chapman RW, Arborgh BA, Rhodes JM, Summerfield JA, Dick R, Scheuer PJ, et al. Primary sclerosing cholangitis: a review of its clinical features, cholangiography, and hepatic histology. Gut 1980;21:870-877.

20. Gershwin ME, Mackay IR, Sturgess A, Coppel RL. Identification and specificity of a cDNA encoding the $70 \mathrm{kd}$ mitochondrial antigen recognized in primary biliary cirrhosis. J Immunol 1987;138:3525-3531.

21. Van de Water J, Gershwin ME, Leung P, Ansari A, Coppel RL. The autoepitope of the $74-\mathrm{kD}$ mitochondrial autoantigen of primary biliary cirrhosis corresponds to the functional site of dihydrolipoamide acetyltransferase. J Exp Med 1988;167:1791-1799.

22. Van de Water J, Surh CD, Leung PS, Krams SM, Fregeau D, Davis P, et al. Molecular definitions, autoepitopes, and enzymatic activities of the mitochondrial autoantigens of primary biliary cirrhosis. Semin Liver Dis 1989; 9:132-137.

23. Migliaccio C, Nishio A, Van de Water J, Ansari AA, Leung PS, Nakanuma $\mathrm{Y}$, et al. Monoclonal antibodies to mitochondrial E2 components define autoepitopes in primary biliary cirrhosis. J Immunol 1998;161:51575163.

24. Miyakawa H, Tanaka A, Kikuchi K, Matsushita M, Kitazawa E, Kawaguchi N, et al. Detection of antimitochondrial autoantibodies in immunofluorescent AMA-negative patients with primary biliary cirrhosis using recombinant autoantigens. Hepatology 2001;34:243-248.

25. Moteki S, Leung PS, Coppel RL, Dickson ER, Kaplan MM, Munoz S, et al. Use of a designer triple expression hybrid clone for three different lipoyl domain for the detection of antimitochondrial autoantibodies. HEPATOLOGY 1996;24:97-103.

26. Drudi Metalli V, Mancino MG, Mancino A, Torrice A, Gatto M, Attili $\mathrm{AF}$, et al. Bile salts regulate proliferation and apoptosis of liver cells by modulating the IGF1 system. Dig Liver Dis 2007;39:654-662.

27. Guicciardi ME, Gores GJ. Bile acid-mediated hepatocyte apoptosis and cholestatic liver disease. Dig Liver Dis 2002;34:387-392.

28. Vantieghem K, Overbergh L, Carmeliet G, De Haes P, Bouillon R, Segaert S. UVB-induced $1,25(\mathrm{OH}) 2 \mathrm{D} 3$ production and vitamin $\mathrm{D}$ activity in intestinal CaCo-2 cells and in THP-1 macrophages pretreated with a sterol Delta7-reductase inhibitor. J Cell Biochem 2006;99:229-240.

29. Matsumura S, Van De Water J, Leung P, Odin JA, Yamamoto K, Gores GJ, et al. Caspase induction by $\operatorname{IgA}$ antimitochondrial antibody: $\operatorname{IgA}$ mediated biliary injury in primary biliary cirrhosis. HePATOLOGY 2004;39: 1415-1422.

30. Henson PM. Dampening inflammation. Nat Immunol 2005;6:11791181.

31. Huynh ML, Fadok VA, Henson PM. Phosphatidylserine-dependent ingestion of apoptotic cells promotes TGF-beta 1 secretion and the resolution of inflammation. J Clin Invest 2002;109:41-50.

32. Casciola-Rosen LA, Anhalt G, Rosen A. Autoantigens targeted in systemic lupus erythematosus are clustered in two populations of surface structures on apoptotic keratinocytes. J Exp Med 1994;179:1317-1330.

33. Herrmann M, Voll RE, Zoller OM, Hagenhofer M, Ponner BB, Kalden JR. Impaired phagocytosis of apoptotic cell material by monocyte-derived macrophages from patients with systemic lupus erythematosus. Arthritis Rheum 1998;41:1241-1250.

34. Canbay A, Feldstein AE, Higuchi H, Werneburg N, Grambihler A, Bronk $\mathrm{SF}$, et al. Kupffer cell engulfment of apoptotic bodies stimulates death ligand and cytokine expression. HePATOLOGY 2003;38:1188-1198.

35. Canbay A, Taimr P, Torok N, Higuchi H, Friedman S, Gores GJ. Apoptotic body engulfment by a human stellate cell line is profibrogenic. Lab Invest 2003;83:655-663.

36. Invernizzi P, Crosignani A, Battezzati PM, Covini G, De Valle G, Larghi A, et al. Comparison of the clinical features and clinical course of antimitochondrial antibody-positive and -negative primary biliary cirrhosis. Hepatology 1997;25:1090-1095.

37. Shimoda S, Harada K, Niiro H, Yoshizumi T, Soejima Y, Taketomi A, et al. Biliary epithelial cells and primary biliary cirrhosis: The role of liverinfiltrating mononuclear cells. HePATOLOGY 2008;47:958-965.

38. Yang GX, Lian ZX, Chuang YH, Moritoki Y, Lan RY, Wakabayashi K, et al. Adoptive transfer of $\mathrm{CD}^{+}{ }^{+} \mathrm{T}$ cells from transforming growth factor beta receptor type II (dominant negative form) induces autoimmune cholangitis in mice. Hepatology 2008;47:1974-1982.

39. Reinsmoen NL, Cornett KM, Kloehn R, Burnette AD, McHugh L, Flewellen BK, et al. Pretransplant donor-specific and non-specific immune parameters associated with early acute rejection. Transplantation 2008;85: 462-470.

40. Mao TK, Lian ZX, Selmi C, Ichiki Y, Ashwood P, Ansari AA, et al. Altered monocyte responses to defined TLR ligands in patients with primary biliary cirrhosis. HePATOLOGY 2005;42:802-808.

41. Kikuchi K, Lian ZX, Yang GX, Ansari AA, Ikehara S, Kaplan M, et al. Bacterial CpG induces hyper-IgM production in CD27(+) memory B cells in primary biliary cirrhosis. Gastroenterology 2005;128:304-312.

42. Charlotte F, L'Hermine A, Martin N, Geleyn Y, Nollet M, Gaulard P, et al. Immunohistochemical detection of bcl-2 protein in normal and pathological human liver. Am J Pathol 1994;144:460-465.

43. Kimura Y, Leung PS, Kenny TP, Van De Water J, Nishioka M, Giraud AS, et al. Differential expression of intestinal trefoil factor in biliary epithelial cells of primary biliary cirrhosis. HePATOLOGY 2002;36:1227-1235.

44. Chatenoud L, Bluestone JA. CD3-specific antibodies: a portal to the treatment of autoimmunity. Nat Rev Immunol 2007;7:622-632.

45. Oertelt S, Lian ZX, Cheng CM, Chuang YH, Padgett KA, He XS, et al. Anti-mitochondrial antibodies and primary biliary cirrhosis in TGF-beta receptor II dominant-negative mice. J Immunol 2006;177:1655-1660.

46. Irie J, Wu Y, Wicker LS, Rainbow D, Nalesnik MA, Hirsch R, et al. NOD.c3c4 congenic mice develop autoimmune biliary disease that serologically and pathogenetically models human primary biliary cirrhosis. J Exp Med 2006;203:1209-1219.

47. Wakabayashi K, Lian ZX, Moritoki Y, Lan RY, Tsuneyama K, Chuang $\mathrm{YH}$, et al. IL-2 receptor alpha(-/-) mice and the development of primary biliary cirrhosis. HePATOLOGY 2006;44:1240-1249. 